\title{
EXPERIMENTAL INVESTIGATION AND NUMERICAL ANALYSIS OF CURVED GLASS PLATES UNDER PRESSURE LOAD
}

\author{
Kandil, K.S.A., EL Abd, M., Hekel, G. and Ghoneim, R.S. \\ Department of Civil Engineering, Faculty of Engineering, \\ Menoufia University, Egypt
}

\begin{abstract}
:
Curved glass plates are used as curtain walls in modern buildings for architectural requirements, which makes them exposed to wind load pressure. In this research, an experimental test and finite element analysis are carried out to investigate the behavior of curved glass plates under uniform pressure loads. Thin curved aluminum plate was tested simulating a monolithic glass plate due to the similarity of modulus of elasticity and Poisson's ratio in both aluminum and glass [1]. In order to simulate a uniform pressure loading on the tested plate, an enclosed chamber was manufactured as a supporting system for the tested plate which was glued with the chamber using structural silicon sealant. The internal air in the chamber was sucked out to simulate the positive pressure on the outside surface of the tested plate. Displacement transducers and strain gauges were mounted on the tested system to measure the displacements and strains as the pressure was reduced inside the chamber. Numerical sensitivity analysis was made using ABAQUS 6.14 software to find out the suitable element type and support conditions that could simulate the experimental model. Results of analysis were presented and discussed. It was found that the 8-node solid element could not represent the curved plate. On the other hand, 20-node solid element could simulate curved glass plate but showed higher failure load. The best element that could simulate the thin curved glass plate is found to be shell element in the current study.
\end{abstract}

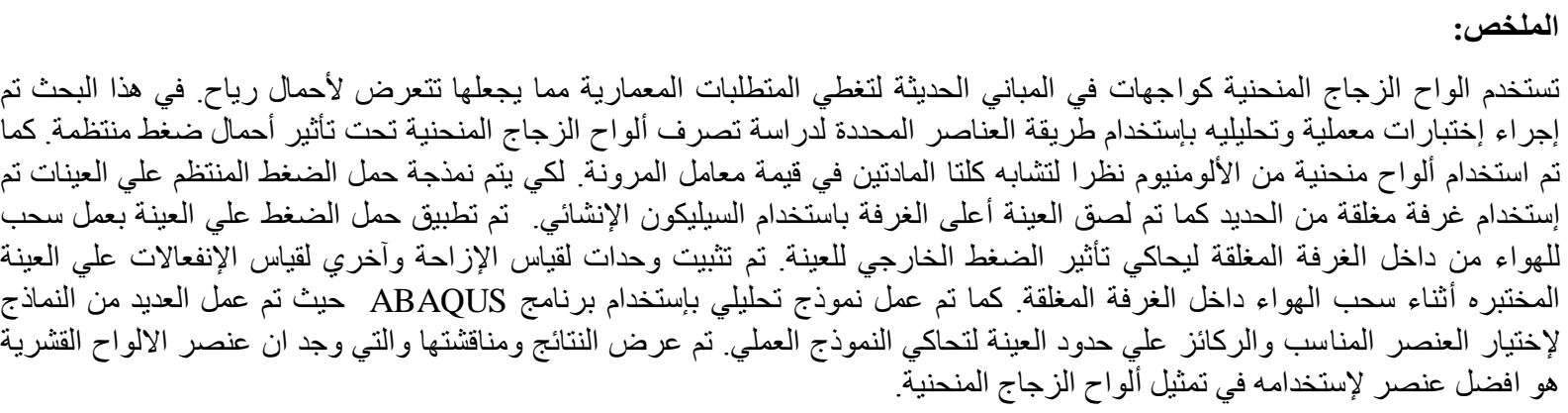

\section{INTRODUCTION}

Recently, curved glass units have become widely used in modern residential and commercial buildings for architectural requirements; see Fig. (1). Window glass plates are usually secured in a framing system with rubber-like gaskets as shown in Fig. (2). It is reasonable to assume that the edges of the plates move elastically in the lateral and in-plane directions and free to rotate about the axes parallel to the edges of the plate.

The major difficulty that faces the designers is the absence of an authoritative resource that provides them with an insight into the structural behavior of curved glass units. Besides, no enough analysis is known for these structures, and further research to analyze them is needed [1].

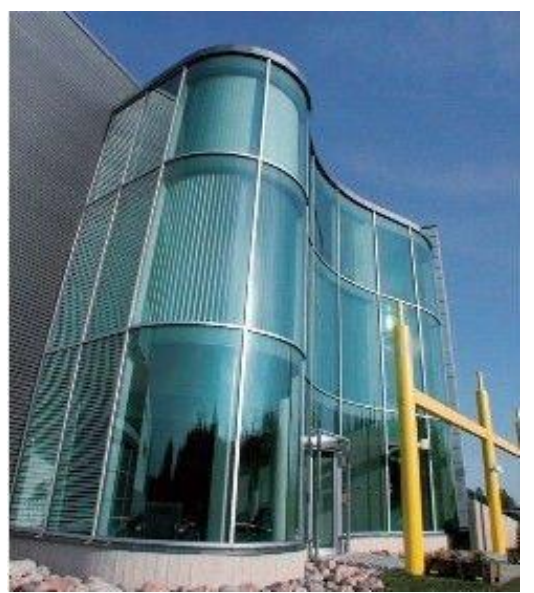

Fig. 1: Curved glass plates as curtain wall

(C) Faculty of Engineering, MenoufiaUniversity, Egypt 


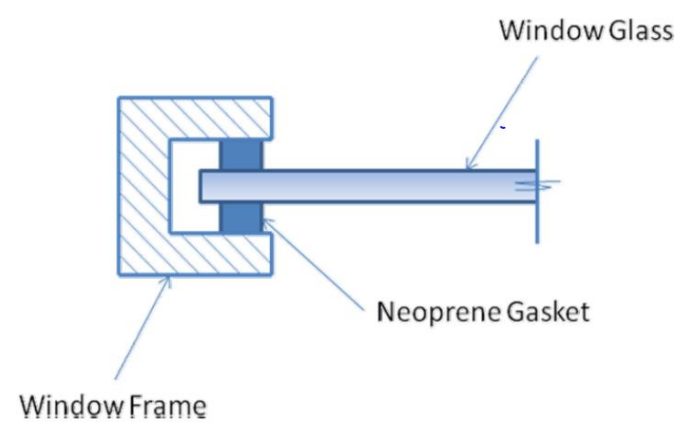

Fig. 2: Window Frame System

A glass type factor is a multiplying factor that relates the load resistance of a specific glass type to the basic load resistance of monolithic annealed glass. Aspect ratio, flexibility ratio, and load set duration are the basis for these glass type factors. Aspect ratio denotes the ratio of the long dimension of the glass to the short dimension of the glass. Flexibility ratio denotes the ratio of the short dimension of the glass to its nominal thickness. According to ASTM [2] there is only one load duration now which is 3 sec.

Levy [3] conducted a formulation for nonlinear analysis of simply supported plates with zero in plane reaction at the edge, which is not suitable for glass plates. El-Shami et al [4] developed a new finite element model for nonlinear analysis of monolithic rectangular glass plates that is capable of handling thin or thick plates. El-Shami and Norville [5] developed a sophisticated finite element model for laminate glass (LG) plates. Philip et al. [6] developed analytical program to analyze curved plate elements. Numerical analysis is carried out by abstracting the procedural development of the theory and programming it to run in a visual basic platform. Asik et al. [7], also developed a mathematical model for Laminated curved glasses for their analysis and safer design. Results of this model are compared with the results from the experiments and finite element model. Guminiak and Szajek [8] introduced a static analysis of circular and elliptic Kirchhoff plates resting on internal elastic supports by the Boundary Element Method. Elastic support has the character of Winklertype elastic foundations. Fildhuth and Knippers [9], in their study, they used curved (heat or cold) bent glass for assembling full glass shells. They focused on the interaction of structure, geometry, glass elements and joining of full glass shells. Bagger [10] investigated the non-linear behavior of a plate shell structure for varying parameters, such as facet size, imperfections, and connection characteristics.

The objective of this paper is to investigate the effect of pressure load on curved glass plates as curtain walls.

\section{EXPERIMENTAL PROGRAM}

\subsection{Test specimen}

A curved aluminum plate was tested to simulate a curved monolithic glass plate. The plate has dimensions of $(1,000 \times 1,000 \times 1.9) \mathrm{mm}$ and a radius of curvature of 1,000 $\mathrm{mm}$ as shown in Fig. (3).

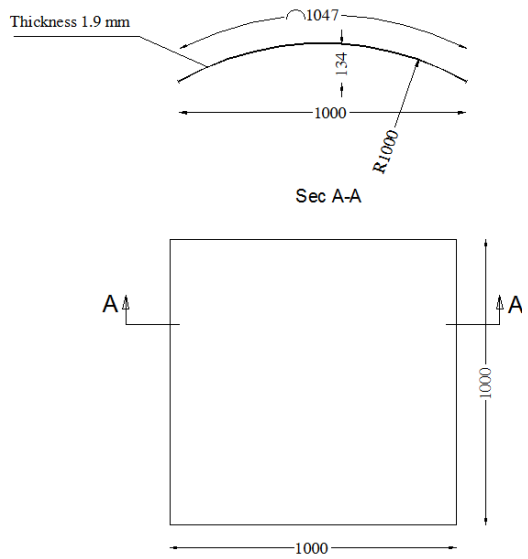

Fig. 3: Geometry of aluminum plate.

\subsection{MATERIAL PROPERTIES}

Aluminum plate of type Al1050, with modulus of elasticity $70 \mathrm{GPa}$ almost the same for monolithic glass mechanical properties [1].

\subsection{TEST SETUP}

\subsubsection{Chamber preparations}

A closed chamber was prepared and assembled in the workshop of the Production Engineering Department, Faculty of Engineering, Menoufia University. The chamber consists of steel plates of $4.0 \mathrm{~mm}$ thickness and equal angles of dimensions $(60 \times 60 \times 5) \mathrm{mm}$. The dimensions and cross sections of the chamber are shown in Fig. (4). In order to manufacture the chamber, the steel plates were cut to the required dimensions and then assembled together using fillet weld connections. Two horizontal angles were welded along the edges as stiffeners. The final chamber shape is shown in Fig. (5). A 12 mm diameter hole was made in the side of the chamber's body, as shown in figure, to suck the internal air using ejector through creating a negative pressure on the plate.

\subsubsection{Specimen setup and measuring devices}

The aluminum plate was connected to the chamber using structural silicone sealant. The locations of strain gauges and displacement transducers are shown in Fig. (6).

Five strain gauges were installed to measure the strain at different points of the tested plate. Two Linear variable differential transformers (LVDT) were placed at middle and quarter of span, Pressure transducer was used to measure the pressure inside the chamber. To collect the measurements from previous mentioned 
devices, they were connected to data acquisition system. The testing equipment and the test setup are shown in Fig. (7).

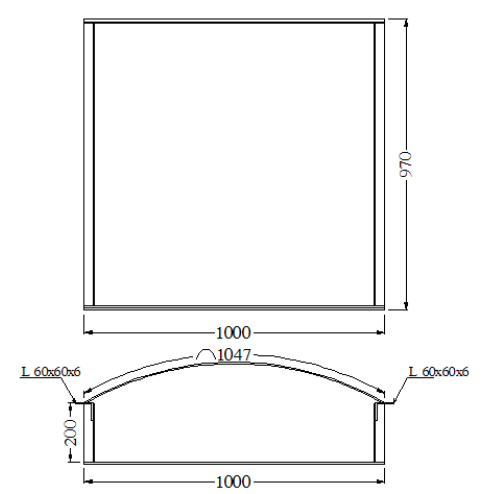

Fig. 4: The chamber model dimensions

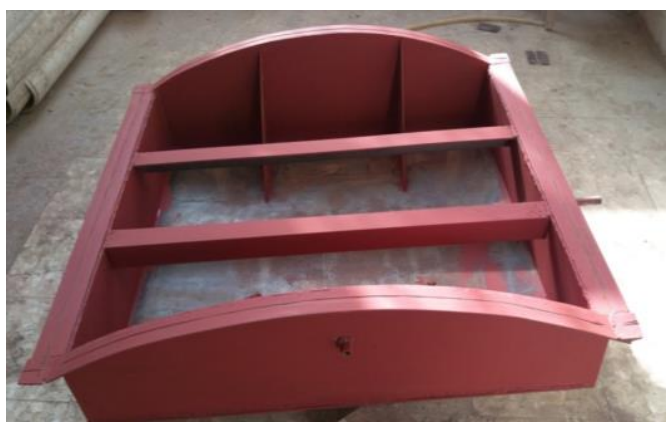

Fig. 5: Final chamber shape
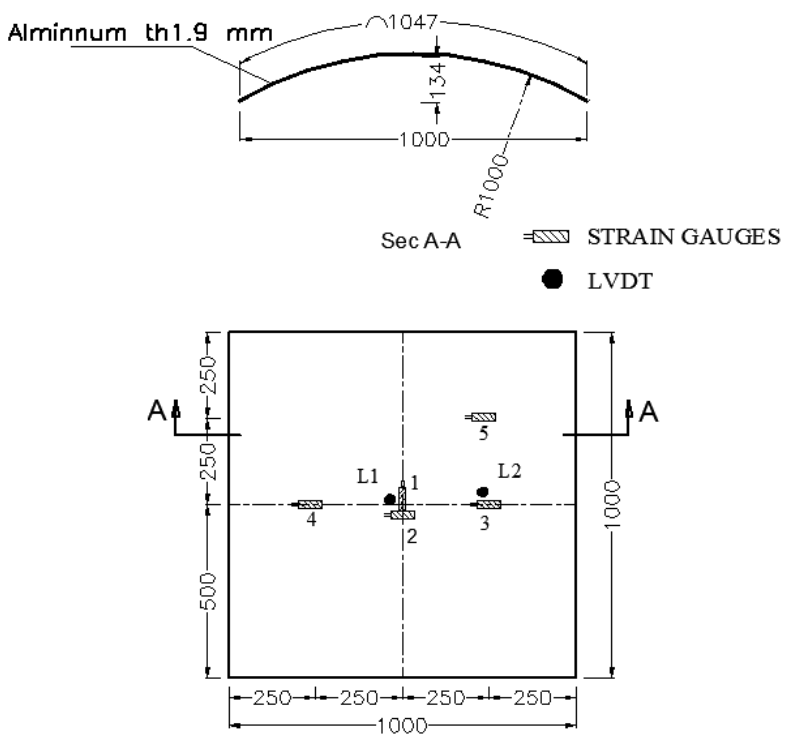

Fig. 6: Measuring devices locations

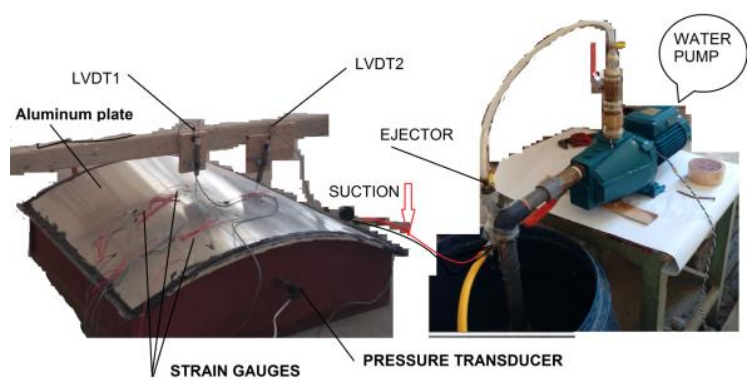

Fig. 7: Test setup and instrumentations

\section{RESULTS OF EXPERIMENTAL STUDY}

\subsection{Load deflection behavior}

As shown in Figs. (8) and (9), the vertical displacements measured by (LVDT1) and (LVDT2) vs. pressure are presented. The plate had risen at its centerline and given positive displacement because the plate centerline at crest point worked as stiffener to the plate. On the other hand, the line along plate`s quarter had a negative vertical displacement. The deformed shape at failure is shown in Fig. (10). At load about $3.5 \mathrm{kpa}$ the model had displacement of 2.5 $\mathrm{mm}$ and $3.5 \mathrm{~mm}$ at the center and quarter of plate, respectively.

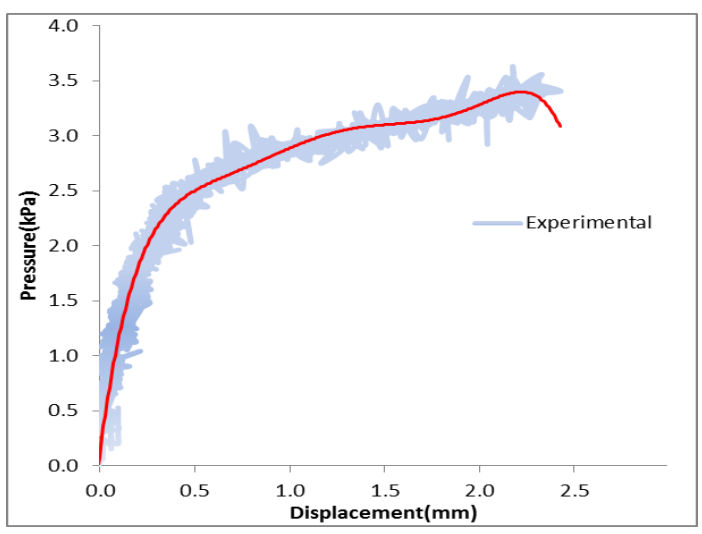

Fig. 8: Load-Deflection curve at mid-span (LVDT1)

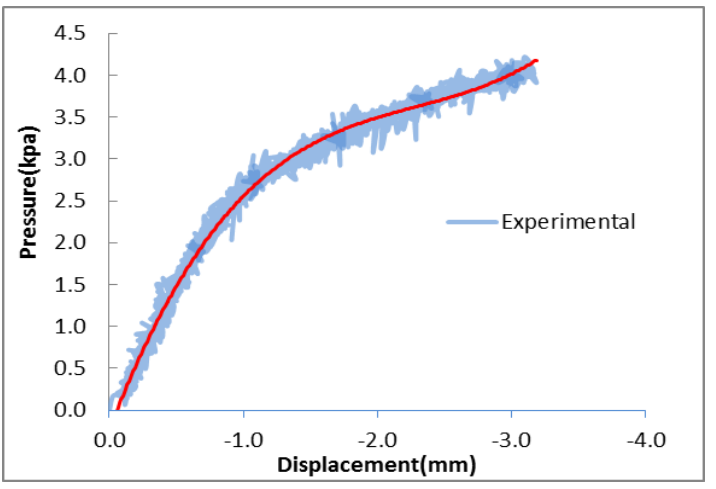

Fig. 9: Load-Deflection curve at quarter (LVDT2) 


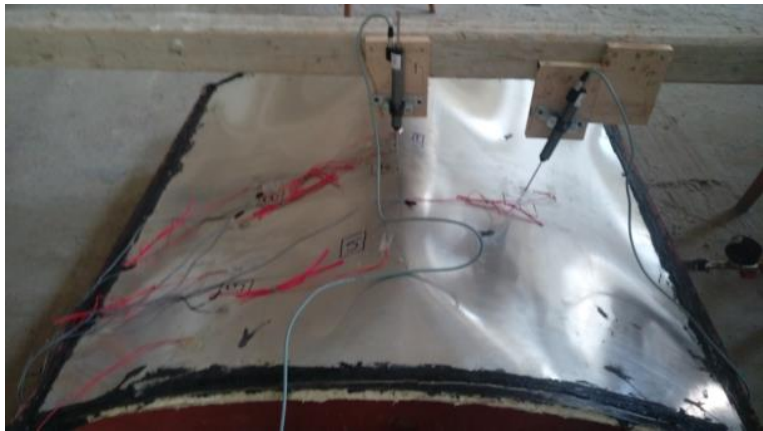

Fig. 10: Deformation shape at failure of aluminum plate

The load-strain curves for points 1 to 5 are shown in Figs. (11) to (14). It can be observed that, at point 1 the strain is positive as a result of tension part along centerline of plate. The strain at point 2 was started as a compression in $\mathrm{Y}$ direction then it converted to tension. The strains at points 3 and 5 have the same sign and shape as they were at the same line.

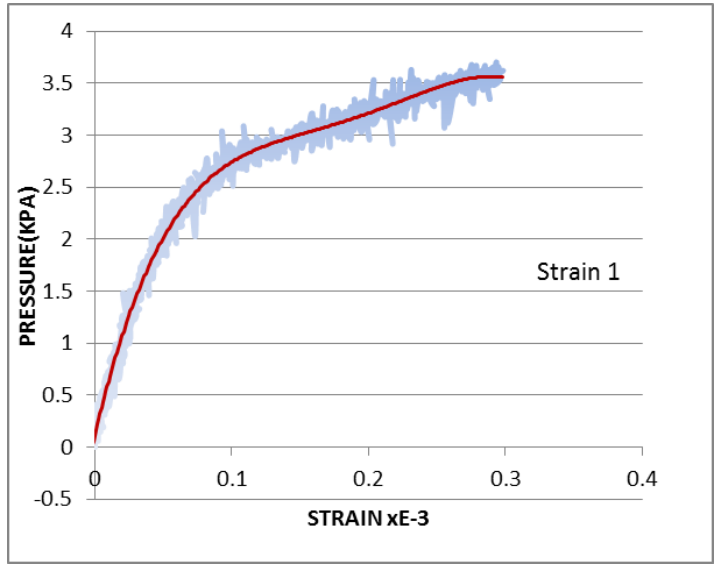

Fig. 11: The pressure-strain curve at point 1

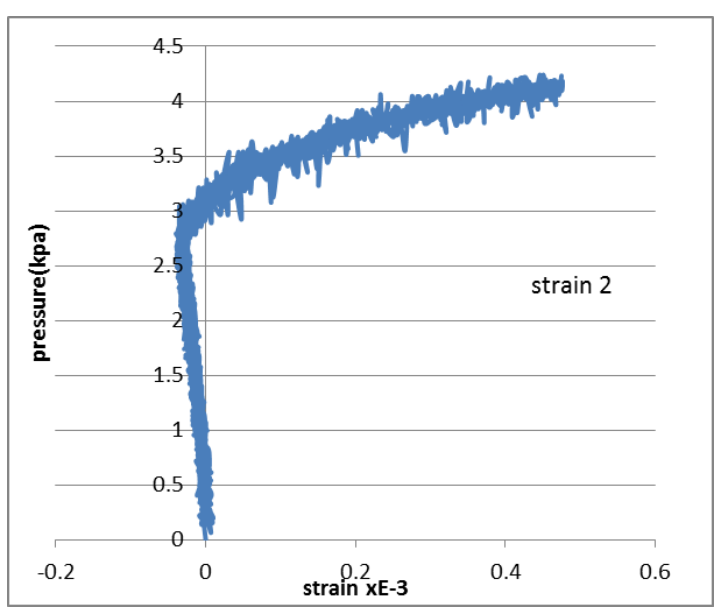

Fig. 12: The pressure-strain curve at point 2

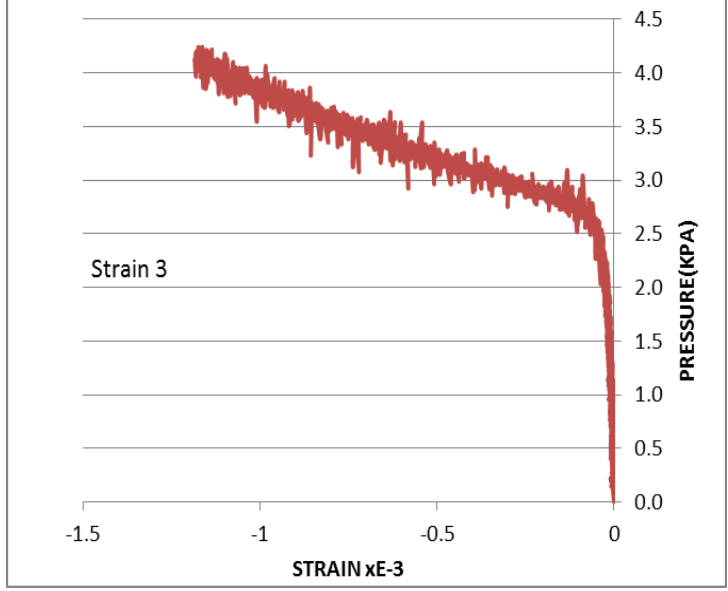

Fig. 13: The pressure-strain curve at point 3

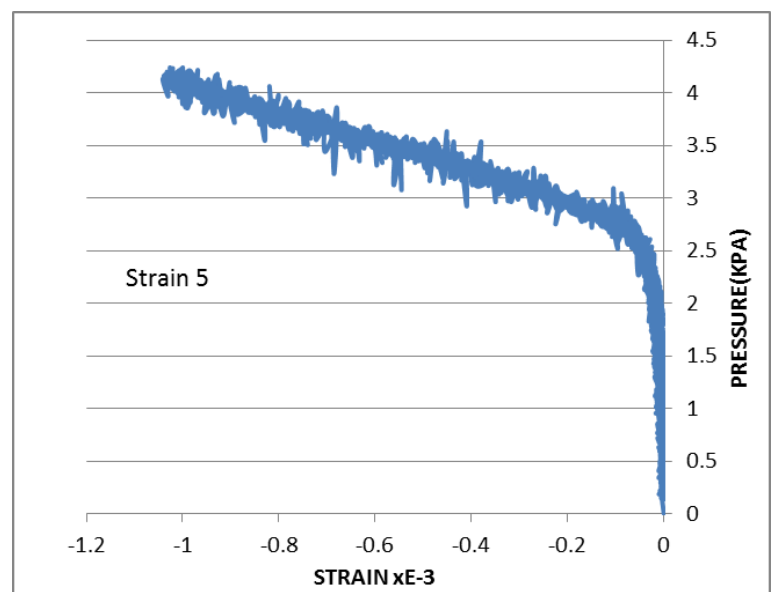

Fig. 14: The pressure-strain curve at point 5

\section{Finite Element model}

This section describes briefly the simulation of curved glass under effect of wind load using finite element model by Abaqus program [11]. Since, there are no enough studies on curved glass plates; a sensitivity analysis has been performed in order to find out the suitable element and support conditions that represent accurately experimental conditions. The first step towards that goal is selecting the suitable element from Abaqus library, then selecting the most appropriate boundary conditions that give the closest results to experimental measurements.

\subsection{Solid element}

The solid (or continuum) elements in Abaqus can be used for linear analysis as well as complex nonlinear analyses involving contact, plasticity, and large deformations.

The curved glass plate was modelled in the analysis using 8-noded solid elements (C3D8), then 20-noded solid element C3D20 as shown in Fig. (15) [11].

In the analysis, glass was modeled as a linear elastic material, with the modulus of elasticity of $70 \mathrm{GPa}$ and 
the Poisson's ratio of 0.22 [1]. Non-linear geometrical behavior was taken into consideration during analysis. Several mesh sizes were tried to reach a reasonable mesh, then the element size was taken $20 \mathrm{~mm} \times 20 \mathrm{~mm}$ as shown in Fig. (16). Boundary conditions were considered as simply supported at edges and fixed at one point in z-direction for stability of model to simulated the silicon behavior as seen in Fig. (17). Pressure load was applied with value of $30 \mathrm{kpa}$ by increments $1 \%$.

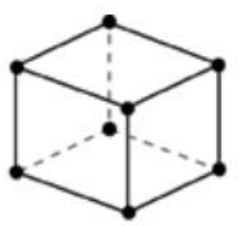

(a) Linear element (8-node brick, C3D8)

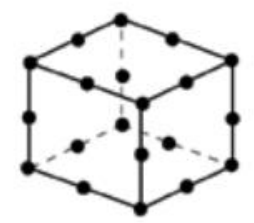

(b) Quadratic element (20-node brick, C3D20)
Fig. 15: Solid element in Abaqus

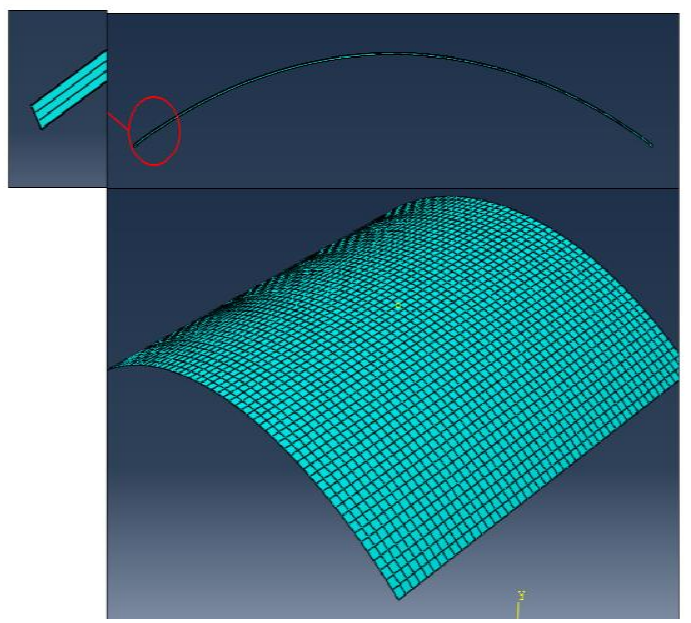

Fig. 16: Finite element on Abaqus. (Solid element)
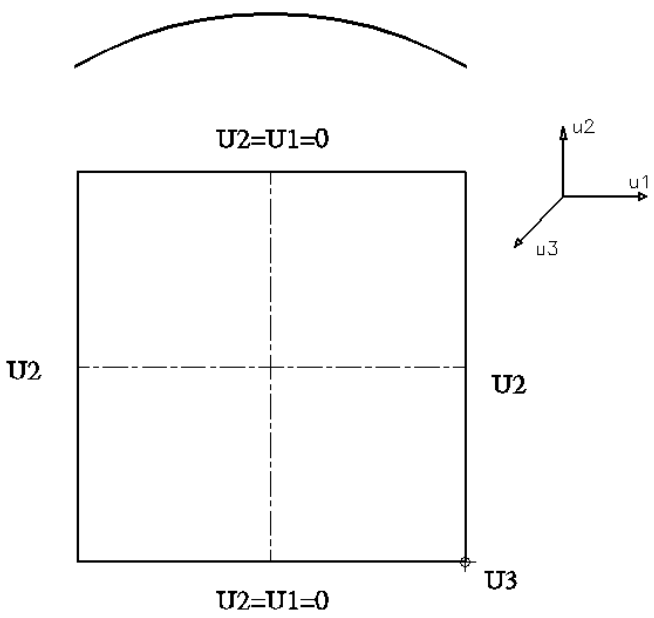

As shown in Fig. (18), the result of vertical displacement vs. pressure at the center of FEM for solid element indicates that 20-node solid element shows closer load-deflection curve to the experimental one.

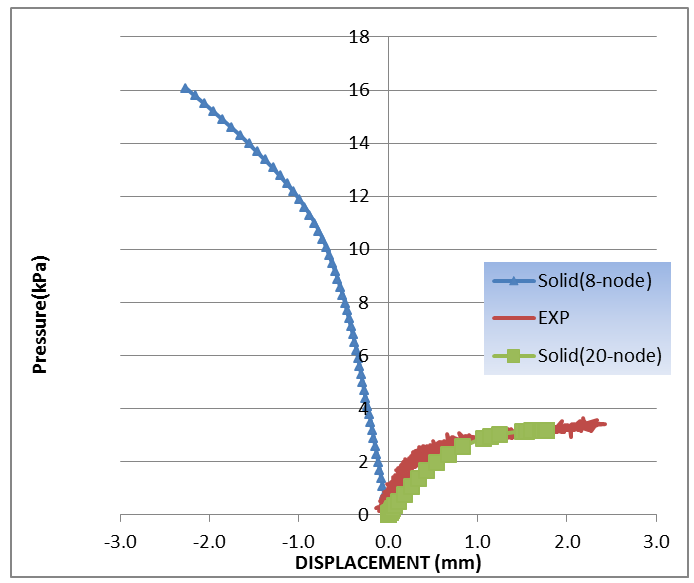

Fig. (18): Vertical displacement at center of plate vs. pressure.

\subsection{Shell element}

Shell element is a one-dimension element, in which, the thickness, is significantly smaller than the other dimensions. Conventional shell elements use this condition to discretize a body by defining the geometry at a reference surface. In this case, the thickness is defined through the section property definition. Conventional shell elements have displacement and rotational degrees of freedom [3]. For the current study, the shell element S8R was selected to model the glass plate. The node numbering and the direction of the normal to the surface are shown in Fig. (19) [11].

In this model, the same material properties and boundary conditions were same as the previous ones. The vertical load-displacement relation at the center of model is shown in Fig. (20).

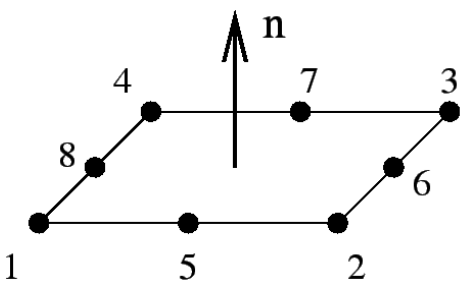

Fig. (19): 8-node quadratic element

Fig. 17: Boundary conditions 


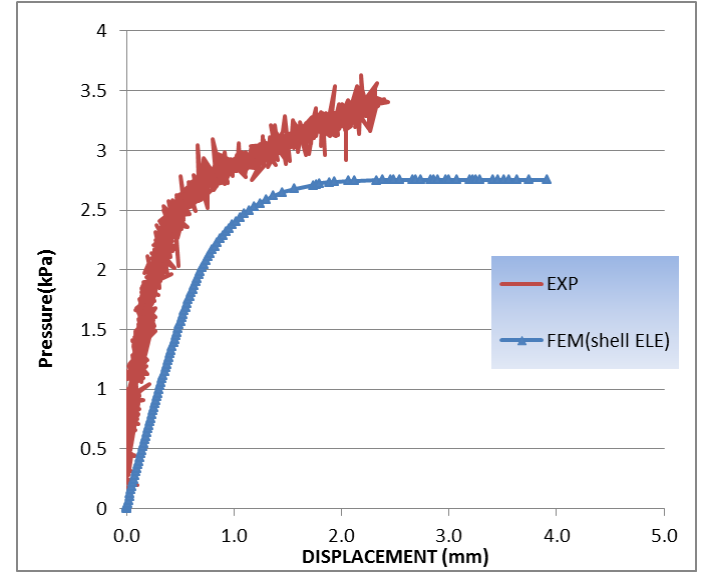

Fig. (20): Vertical displacement at center of plate vs. pressure.

As mentioned before and shown in Fig. (18), the result obtained from 8-node solid element does not represent the real behavior of the curved glass plate. The comparison between shell element and the 20-nodes solid element with experimental result is presented in Fig. (21). It is obvious that, the load-deflection curve from solid element model shows a closer stiffness to the experimental one. However, it shows higher yielding pressure. On the other hand, the shell element has almost the same yield load as shown in Fig. (22). So, shell element is selected for further analysis.

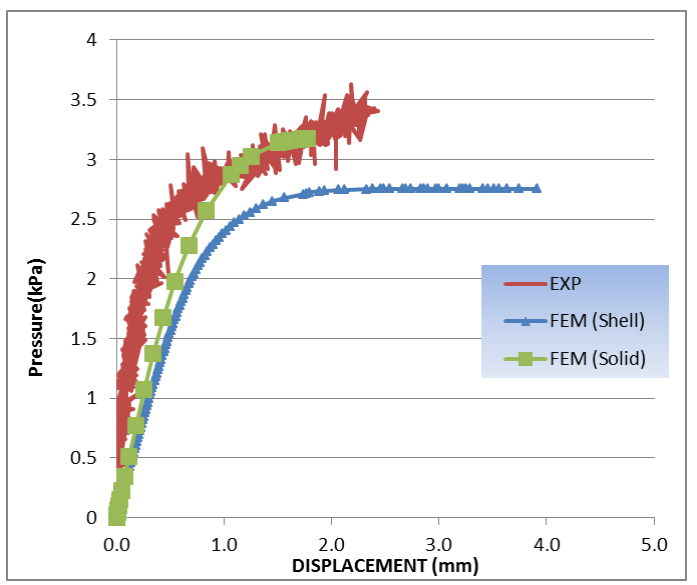

Fig. (21): Comparison between the results of shell and solid element vs. experimental results.

\subsection{Boundary conditions simulation}

In this part, five trials have been carried out to simulate the true boundary condition that simulates the experiment work. The summary of these trials is presented in Table (1).
Table (1): The trials of boundary conditions in Abaqus

\begin{tabular}{|c|c|c|c|}
\hline Trials & Description & Simply supported \\
with one corner \\
prevented from \\
displacement in \\
U3 dirction
\end{tabular}

\section{RESULTS AND DISCUSSION}

Fig. (22) sums the comparison between the results obtained from the numerical models using Abaqus program and the experimental results. Clearly, the closest curve to experimental one is that obtained from trial 5. The deformed shape is almost the same of experimental model as shown in Fig. (23). 


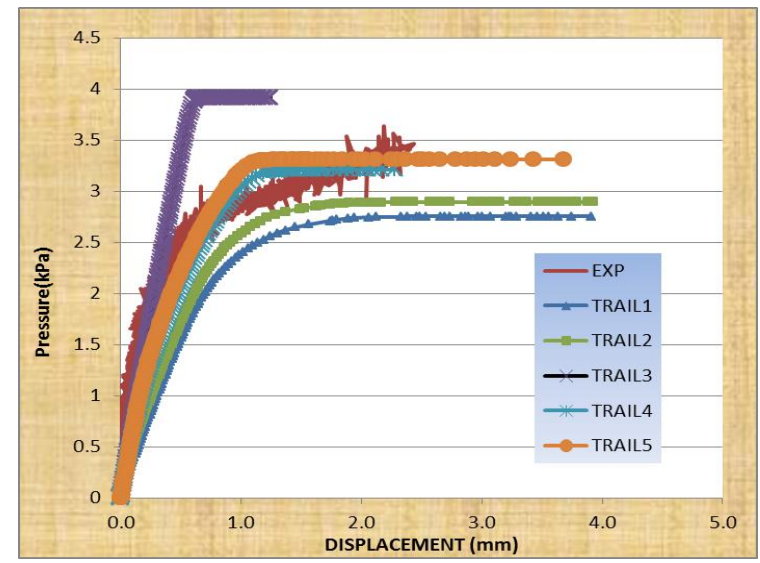

Fig. (22): Comparison between shell and solid elements

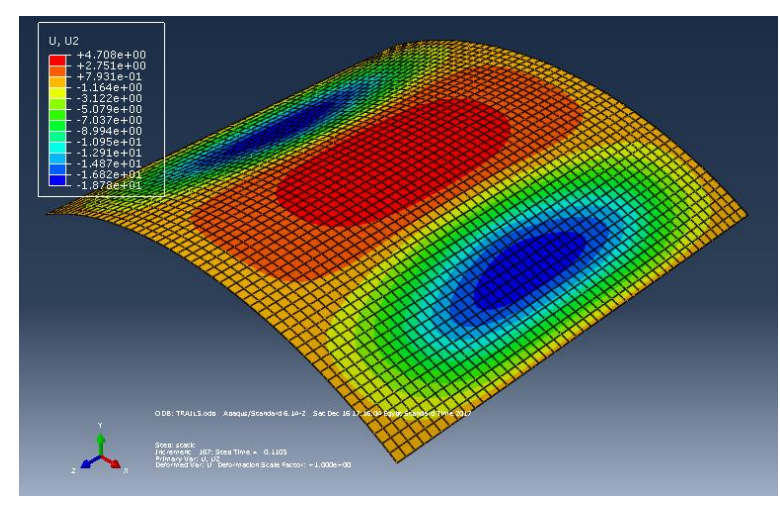

Fig. (23): deformed shape of trial 5 model

\section{Conclusions}

Experimental program was conducted on a curved aluminum plate to simulate curved glass plate as curtain wall because aluminum and glass almost have the same modulus of elasticity and poison's ratio. Also finite element program was used to simulate the experimental case of study and to investigate the best way to simulate curved glass plate. Based on the above findings, the following conclusions can be drawn:

1. During the experiment, the tested plate had risen along the center line and given positive displacement because the plate center line at crest point worked as stiffener to the plate while the line along plate`s quarter had a negative vertical displacement.

2. The 8-node solid element could not represent the curved plate. On the other hand, 20-node solid element could simulate curved glass plate but showed higher failure load.

3. The best element that could simulate the thin curved glass plate is the shell element in the current study.

4. The closest results obtained from finite element model to the experimental measurements were achieved when boundary conditions were simply supported with 7 springs added in U3 direction along the two straight edges and preventing the four corners from displacement at U3 direction.

\section{References}

[1] El-Shami, M.M., "Nonlinear analysis of folded plate structures, " Ph.D Thesi. Civil Engineering Department, Minufiya University, 1997.

[2] ASTM, "Standard Practice for Determining Load Resistance of Glass in Critical Facilities," ASTME1300-. West Conshohocken, PA, USA. UNIVERSITY, 2004.

[3] Levy, S., "Bending of Rectangular Plates with Large Deflection," NACA,Technical Note, vol. No. 846, 1, 1942.

[4] El-Shami, M.M., Vallabhan, C.V.G., Kandil, K.S. and Tawfik, O.M. "Experimental Verification of Folded Glass Plates Used in Architectural Window Glazing," Trans. Model. Simul., vol. 6, pp. 11-21, 1997.

[5] El-Shami, M.M. and Norville, H.S. "Finite element modeling of architectural laminated glass." IES Journal Part A: Civil and Structural Engineering 4 (1), 2011.

[6] Philip, M. “Analysis of Curved Plate Elements using Open Source," International Journal of Scientific and Research Publications, vol. 4, no. 7, pp. 1-7, 2014.

[7] Aşik, M. Z., Dural, E., Yetmez, M. and Uzhan, T. "A mathematical model for the behavior of laminated uniformly curved glass beams," Composite. Part B Eng., vol. 58, pp. 593-604, 2014.

[8] Guminiak, M. and Szajek, K., "Static Analysis of Circular and Elliptic Plates Resting on Internal Flexible Supports By The Boundary Element Method," J. Appl. Math. Comput. Mech., vol. 13, no. 2, pp. 21-32, 2014.

[9] Fildhuth, T. and Knippers, J., "Considerations Using Curved, Heat or Cold Bent Glass for Assembling Full Glass Shells," engineered transparency. International Conference at glasstec, Düsseldorf, Germany , no. October, pp. 1-10, 2012.

[10] Bagger, A. "Plate shell structures of glass," Ph.D. ThesisDepartment of Civil Engineering Technical University of Denmark vol. 221, no. April. 2010.

[11] Abaqus program, users and manuals, 6.14. 2014. 